\title{
Advance telephone notification of follow-up in the healthlines study: a nested study of patients with depression
}

\author{
Louisa Edwards' ${ }^{1}$ Chris Salisbury ${ }^{1}$, Katy Garner ${ }^{1}$, Kim Horspool ${ }^{2}$, Alexis Foster ${ }^{2}$, Alan Montgomery ${ }^{3^{*}}$ \\ From 3rd International Clinical Trials Methodology Conference \\ Glasgow, UK. 16-17 November 2015
}

\section{Background}

Advance notification may increase response to follow-up questionnaires among trial participants, but the benefit of this resource-intensive activity remains uncertain. This study investigated the effectiveness of pre-calling participants with depression ahead of follow-up in The Healthlines Study, a trial of a telehealth intervention.

\section{Methods}

Participants in one of the three study centres were alternately allocated to either be telephoned 2-7 days before sending an 8-month follow-up questionnaire by post or email, or to be sent the questionnaire without pre-calling. All participants received up to five questionnaire completion reminders. The primary outcome was completion of the PHQ-9 outcome. Secondary outcomes were number of reminders and time to questionnaire completion.

\section{Results}

201 participants were included in the nested study $(100$ to pre-calling), of a total of 609 in the Healthlines depression trial. Outcome completion was $\geq 90 \%$ in both arms (OR 0.82, 95\% CI 0.31 to 2.19). Participants in the pre-calling arm were less likely to require a reminder ( $47 \%$ vs $62 \%$, OR $0.46,0.25$ to 0.84 ), required fewer reminders (difference in means $-0.6,-1.1$ to -0.2 ), and completed follow-up quicker (median 8 vs 15 days, HR $1.24,0.92$ to 1.66$)$ than participants who received no pre-calling.

\section{Conclusion}

Outcome completion rate at 8-months follow-up was high. There was no evidence that pre-calling participants

${ }^{3}$ University of Nottingham, Nottingham, UK

Full list of author information is available at the end of the article achieved better completion rates, nor reduced overall net effort required to achieve follow-up after taking into account pre-contacting these participants. Pre-calling may be helpful when timing of outcome completion is important.

\section{Authors' details}

${ }^{1}$ University of Bristol, Bristol, Bristol, UK. ${ }^{2}$ University of Sheffield, Sheffield, UK. ${ }^{3}$ University of Nottingham, Nottingham, UK.

Published: 16 November 2015

doi:10.1186/1745-6215-16-S2-P111

Cite this article as: Edwards et al:: Advance telephone notification of follow-up in the healthlines study: a nested study of patients with depression. Trials 2015 16(Suppl 2):P111.
Submit your next manuscript to BioMed Central and take full advantage of:

- Convenient online submission

- Thorough peer review

- No space constraints or color figure charges

- Immediate publication on acceptance

- Inclusion in PubMed, CAS, Scopus and Google Scholar

- Research which is freely available for redistribution
() Biomed Central 